\title{
1. Introduction: the role of small and medium-sized enterprises in achieving and sustaining growth and performance
}

\section{Charles Harvie and Boon-Chye Lee}

\subsection{OVERVIEW}

This volume is the third in a series on small and medium-sized enterprises in East Asia, defined broadly to include the countries along the western rim of the Pacific from Japan and China in the north to Australia and New Zealand in the south, taking in the ASEAN countries along the way. The focus of the first volume was on the changing global economic environment and the role, contribution, problems and opportunities facing SMEs in East Asia (Harvie and Lee, 2002a). The second focused upon the role and contribution of SMEs in a number of countries in East Asia, ranging from developing and transition economies such as China, Vietnam and Indonesia, to the newly industrialized economies of Korea, Taiwan and Malaysia, to the mature developed economies of Australia, New Zealand, Japan and Singapore (Harvie and Lee, 2002b). The focus in the current volume, as the title suggests, is on both how SMEs contribute to achieving and sustaining growth and performance in their economies, as well as the ways in which governments can assist and enhance that contribution. This is of particular concern given the trauma that many of the East Asian economies experienced in the wake of the financial and economic crisis of 1997-98, including severe declines in GDP, rising unemployment and poverty (see for example World Bank, 1998; Tran and Harvie, 2000; and Harvie, 2002). Faced with the need to restructure and reform their economies, putting them on a solid foundation for future sustainable growth, many East Asian countries actively pursued growth of the SME sector, focusing upon the encouragement of entrepreneurialism in the private sector (Hall, 1999a). This was particularly noticeable in the transition economies of Vietnam and China, but also in economies such as 
Korea which had, in the past, given more emphasis to the growth of the large industrial conglomerates.

This chapter briefly reviews the contribution of the SME sector to the sustainable recovery of the region, and in doing so identifies barriers to their development, key factors essential for their capacity building, strategies to enhance their competitiveness in the global marketplace, and key components relating to their export success. In the following section key issues relating to SME development are highlighted. Section 1.3 focuses upon key issues relating to SME capacity building. Section 1.4 focuses upon globalization and the key ingredients for SME export success. Section 1.5 highlights key policy issues. Finally, section 1.6 presents the structure of the remaining chapters of this book.

\subsection{KEY ISSUES}

While the region consists of many diverse, although closely integrated, economies, a common characteristic is the significance of a sizeable and rapidly expanding SME sector. As the first and second volumes of this series indicated (Harvie and Lee, 2002a, 2002b), this sector has considerable potential to provide a solid foundation and contribution to the sustained recovery of the region. This contribution, and type of contribution, will vary by country and be dependent upon a number of factors, including country stage of economic development, country institutions, the nature and extent of domestic entrepreneurialism and innovation, the extent of market opening and competitiveness, access to technology, access to finance, development of human resources, access to market information, an ability to exploit export opportunities either directly or as part of the supply chain of transnational corporations, and market-friendly and supportive government policies. Irrespective of the stage of development of regional economies there are clear trends towards globalization and increased regional economic integration with the opening up of regional markets and increased reliance on exporting (OECD, 1997). In this context it is essential that the full potential of small business exports is exploited. There is evidence to suggest however that SME exports are lagging due to existing difficulties in terms of red tape and the cost of logistics that can make exporting prohibitive (Hall, 2002b).

Since the early 1990s the economies of East Asia, and of APEC more generally, have been opening up their markets and in the process have achieved significant gains in exports and economic growth. In conjunction with this increased economic integration there has been increased recognition by regional governments of the potential for a substantial increase 
in the participation by small businesses in the generation of regional income, employment, exports, investment and expanded economic growth. Advances in information and communications technology have further added credence to this potential. In addition, developing economies are especially seeing small businesses as potential instruments for the alleviation of poverty. Further momentum for this was provided after the financial and economic crisis of 1997-98. The crisis resulted in many of the countries of East Asia: re-evaluating their industrial policies; placing greater emphasis on improving corporate governance; improving the efficiency and competitiveness of their enterprises; and developing business sectors more able to overcome the vicissitudes of domestic, but more importantly global, market developments (Pomerleano, 1998). The latter is of particular importance in the context of increased economic interdependence and open regionalism. The need to develop more adaptable and flexible economies, and business sectors, has resulted in increased emphasis on the development of the SME sector, particularly given the relative resilience of the Taiwanese economy, dominated by SMEs, and the potential platform they provided (Ministry of Economic Affairs, 1999). The SME sector will continue to play a key role in the sustained economic recovery of the region, and this will be made most effective where it is in a position to take best advantage of rapidly increasing business opportunities and in doing business in new ways (for example, developing knowledge-based services and technology-intensive goods, finding market niches, exploiting the Internet and e-commerce, and through global mergers and joint ventures).

A number of observations can be made about the contribution of SMEs as the Entrepreneurial Engine of East Asia (see Hall, 2002a). First, it is clear that SMEs do provide the lion's share of growth. Typically, in the economies for which there are reliable data, about 70 per cent of employment growth comes from SMEs. Anecdotally, even in economies for which there are no data, SMEs play a major role; for example, almost all net employment creation in China, Vietnam and Indonesia since the early 1990s has been in SMEs. In China and Indonesia, for example, large firms have been net job destroyers as they downsize - a phenomenon also common in Europe and the USA.

Second, the 'entrepreneurial engine' is underpowered in much of East Asia, especially in the less-developed economies of China, Indonesia, the Philippines, Thailand and Vietnam (Hall, 2002a). In these economies there are simply fewer SMEs than might be expected. The number of people per SME in these economies is much higher than in the more developed economies (Hall, 2002a). This means that there are fewer start-ups, and the pool of SMEs from which high-growth SMEs can emerge is much smaller. Consequently, there is less growth than there would otherwise be. 
In a very rough order of magnitude calculation, for these economies to achieve a benchmark level of 20 people per SME, there would have to be about 70 million new SMEs created. This needs to be compared with the 20 million or so SMEs in all of East Asia at present. This means 70 million or more people will need managerial skills and training. Most of these are in China but there is also considerable room for advancement in countries such as Indonesia and Thailand. The potential for SME start-ups in countries such as China, Indonesia and Vietnam could be a major source of job creation and growth for these economies in the future (Hall, 2002a).

Third, in developing East Asia the bulk of the SME contribution to growth will probably come from net start-ups, while in developed East Asia, the growth contribution will tend to come more from high-growth firms. Start-up rates tend to be relatively low, especially in Japan, which is the largest economy in the region. Japan's net start-up rate (domestically at least) has been negative for some time. Part of this is the economic downturn, and part of it is cultural and institutional inhibitions to taking risks and starting a business. These cultural and institutional factors need to be actively addressed if East Asia is really to make use of the potential of its entrepreneurial engine.

Fourth, the entrepreneurial engine is being internationalized. For example, a small but significant proportion of SMEs in Japan, Korea and Taiwan have already expanded operations abroad; about 13 per cent of Japan's manufacturing output is now sourced abroad. It is becoming easier for SMEs to operate across borders. This is partly as a result of efforts to reduce trade and non-trade impediments by the WTO, APEC and ASEAN. It is also part of the general globalization of business occurring as a result of improved communications (particularly e-commerce and the Web) and other technological and social changes. This SME internationalization is not limited to specific regions, such as East Asia, but is global.

Table 1.1 summarizes key common features, differences and policy issues in the profile of SMEs in East Asia.

\subsection{SME CAPACITY BUILDING}

For SMEs to participate fully in the process of globalization they must develop capacities enabling them to be internationally competitive in global markets. This will involve building upon the potential advantages already possessed by them - entrepreneurial spirit, flexibility, resourcefulness and an ability to identify business opportunities and market niches based upon their unique products and services. Despite this they face a number of barriers in their development - their small size means that they have limited 


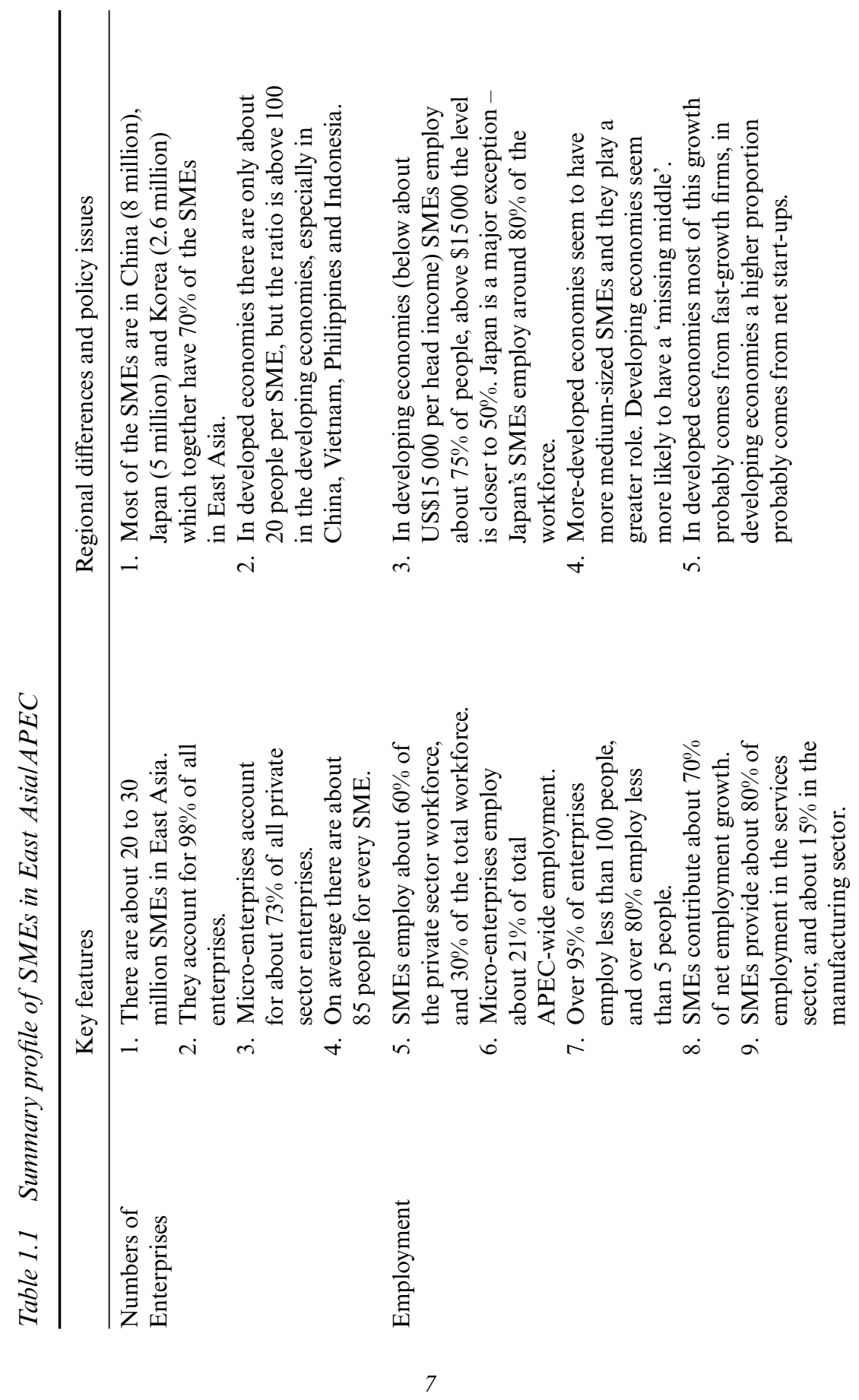




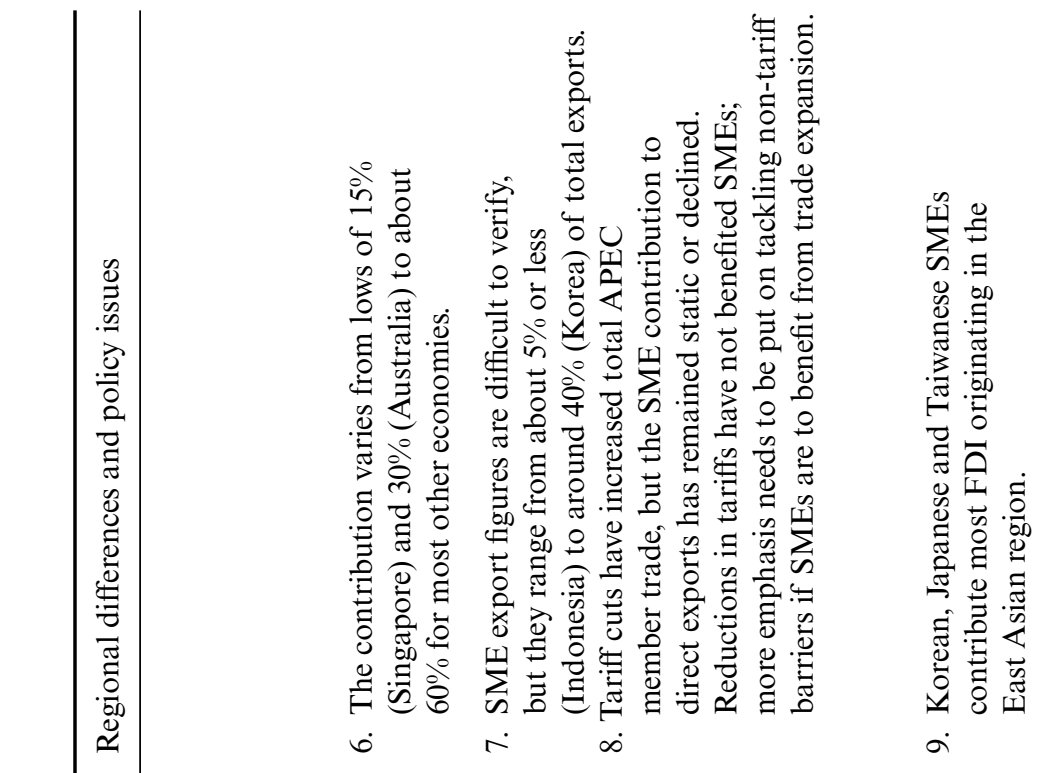

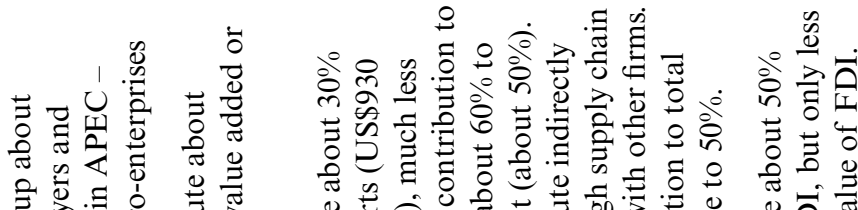

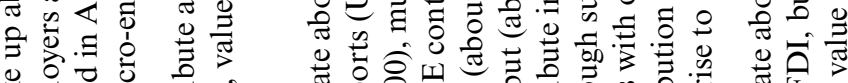

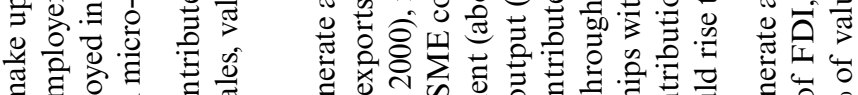

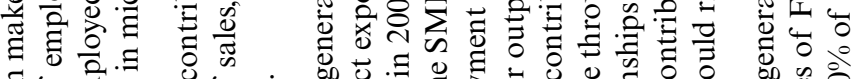
चี

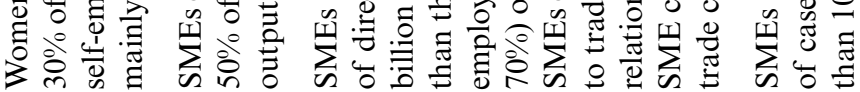

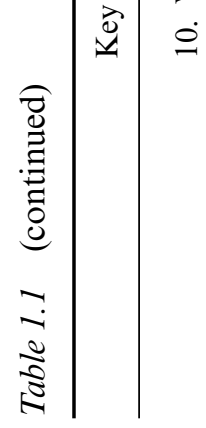
in 


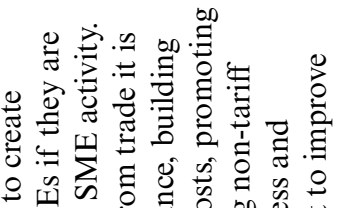

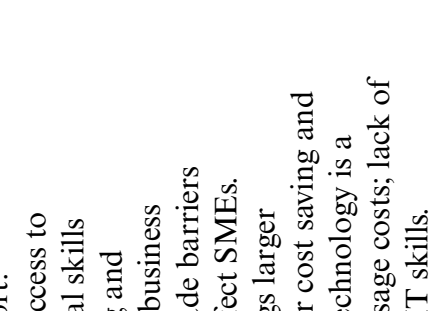

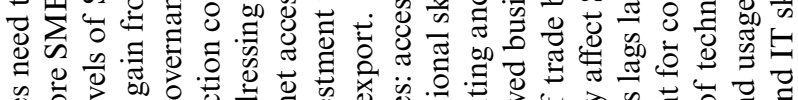

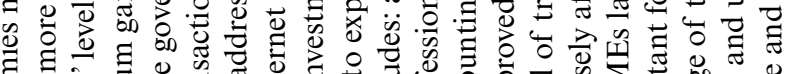

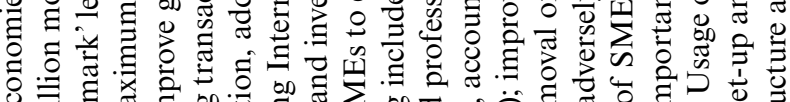

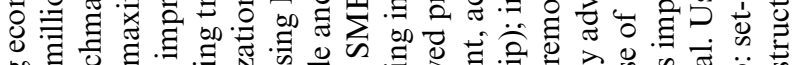

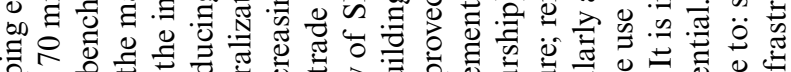

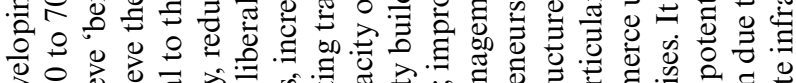

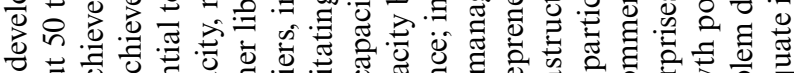

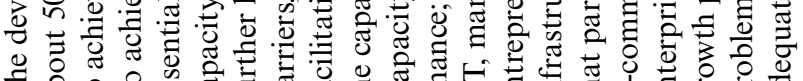

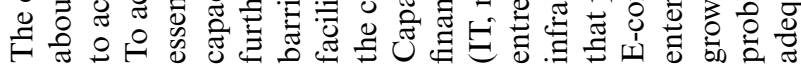

$\dot{0}=$

¿

$\dot{2}$

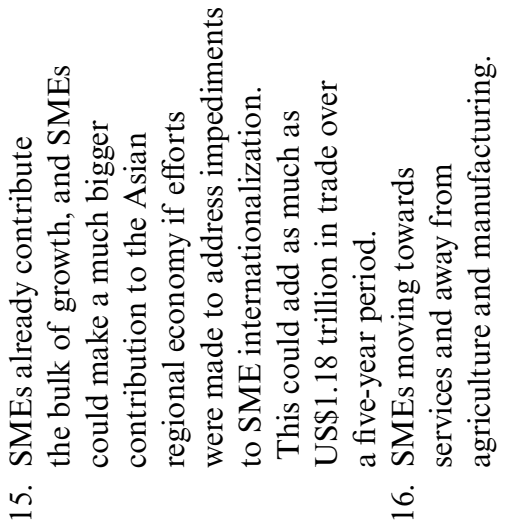

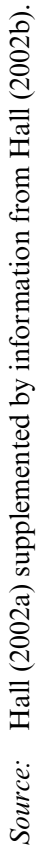

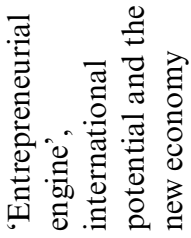


resources and access to finance, they lack economies of scale, they have high relative costs in accessing and utilizing information technology, they have skill deficiencies in the utilization of IT, they have entrepreneurial, managerial, accounting and marketing skill deficiencies, they lack information on market opportunities, they have high transaction costs arising from gaining access to transport infrastructure and the cost of transportation, and from achieving quality accreditation, they lack skills in dealing with customers both in the domestic market and in the export market, they have limited knowledge about language and culture as well as the legal and bureaucratic issues involved in exporting, they may experience a lack of business infrastructure support and in some countries may be discriminated against relative to large firms.

Building capacity, improving governance, reducing transaction costs, promoting further market liberalization, addressing non-tariff barriers, increasing Internet access, and facilitating trade and investment are all directly relevant to improving the capacity of small businesses to exploit export market opportunities and for their regional growth.

At the Ottawa meeting of APEC in September 1997, for example, five key areas of importance to the capacity building of SMEs were emphasized (APEC, 1998). These are access to markets, technology, human resources, financing and information.

\section{- Access to Markets}

It is recognized that SMEs face special problems relating to their size and that, in the context of rapid trade liberalization, they need to develop capacities to take advantage of opportunities arising from a more open regional trading system. The Internet is regarded as being of particular importance in this regard (Hall, 1999b, 2000; OECD, 2000c), as is the need to identify appropriate partners for joint ventures or strategic alliances, to harmonize standards and professional qualifications, including investment laws and taxation procedures, and to harmonize the protection of intellectual property rights.

Despite cuts in average tariffs in APEC from 12 per cent in 1995 to 8 per cent in 2000 , contributing to an estimated growth rate in merchandise exports of 4.7 per cent per annum over this period, small businesses have been unable fully to exploit opportunities to export (Hall, 2002b). The SME contribution to direct exports in APEC has remained static or declined. Reductions in tariffs have not benefited SMEs, and more emphasis by regional governments needs to be put on tackling non-tariff barriers (customs procedures, mobility of business people, standards of labelling requirements, access to finance, recognition of professional qualifications, 
consumer protection particularly regarding on-line transactions, and intellectual property rights) if SMEs are to benefit from trade expansion and to enhance their exporting capacity. Greater participation by SMEs in trade is likely to generate a number of benefits. With access to a larger market, individual firms will be able to benefit from economies of scale and generate additional revenue (Hall, 2002b). In terms of efficiency, firms that expose themselves to more intense competition in global markets can acquire new skills, new technology and new marketing techniques. Exporters tend to apply knowledge and technologies at a faster rate and more innovatively than non-exporters. This can result in greater efficiency and productivity. A larger number of SME exporters assists skill and technology applications by spreading these over many small buyers which extends the gains over the entire economy and not just firms that export. Ultimately the economy will benefit from more flexible and environmentally responsive firms, higher growth rates and long-term improvements in productivity and employment levels. Exporting has a positive effect on living standards, as competition drives firms to invest in staff development, which in turn improves productivity, wages and working conditions. Exporting also encourages cultural diversity and the building of relationships and reputations with other countries.

\section{- Access to Technology}

In a knowledge-based economy, applications of information and communications technology can be a great leveller for SMEs (Hall, 1999b, 2000; OECD, 2000c). However, when SMEs have limited access or understanding of these technologies, their prospects of acquiring and utilizing these for their benefit is reduced. In terms of the Internet, e-commerce use amongst small businesses is currently lagging behind their larger counterparts. However, many small businesses view e-commerce as providing cost savings and growth potential, and the gap relative to larger enterprises is closing, but further action by regional governments will be required (in terms of improved infrastructure, cost and IT training, as well as information relating to the business opportunities that e-commerce can generate). Enhancing the role and participation of small businesses in the global marketplace through e-commerce will be of critical importance. E-commerce presents small businesses with the opportunity to compensate for their traditional weakness in areas such as access to new export markets and competing with larger firms. It can provide global opportunities by enabling the flow of ideas across national boundaries, improving the flow of information and linking increased numbers of buyers and sellers. This provides opportunities for greater numbers of trading partners dealing in goods, 
and increasingly in services. Studies suggest that small businesses with higher levels of e-commerce capabilities are more likely to identify using e-commerce to reach international markets as an important benefit. Hence the desire to export for many SMEs may have a fundamental influence on promoting the rapid development of more advanced e-commerce capabilities. For many small businesses in the Asia-Pacific region, integrating the development of e-commerce into their future strategies for accessing international markets is seen as being crucial (Hall, 1999b). E-commerce also has the potential to lead to cost savings and efficiency gains. Raising the awareness as well as the understanding of the benefits to be obtained from e-commerce will be important in increasing its uptake by small business. To incorporate the technology into their operations small business needs to find ways to deal with high set-up costs, as well as lack of adequate infrastructure and IT skills. If these can be overcome small business will play an important part in the region's 'new economy' at least as much as it will for more traditional forms of commerce. In this regard the role of the government is likely to be crucial. This includes development of the telecommunications infrastructure; addressing legal and liability concerns; ensuring that fair taxation practices are applied to e-commerce; addressing security issues; and raising the awareness of the business benefits of e-commerce, including the potential for export growth.

\section{- Access to Human Resources}

Human resource development for SMEs requires a comprehensive approach including social structures and systems such as broad educational reforms; encouragement of entrepreneurship, business skills acquisition and innovation in society; mechanisms for self-learning and ongoing training and enhancement of human resources; and appropriate governmental support programmes. Among small and micro-enterprises a shortage, and the cost, of skills in information technology are a major hindrance to business growth. Consequently staff training in IT as well as in skills required to successfully enter export markets are required. Improved IT skills would enable more efficient management of the business, workload sharing, and the development of more market opportunities including that of exports. Other desired exporting skills include language and cultural expertise, as well as legal and logistical knowledge.

\section{- Access to Financing}

The opportunity to access small amounts of finance can be an important catalyst for small businesses to get access to the resources they need to gain 
a foothold in the market. This is particularly critical for micro-enterprises. Many SMEs lack awareness of financing resources and programmes available from commercial banks and other private sector and government sources, and they have difficulty defining and articulating their financing needs. Financial institutions need to be responsive to their needs and for continuing simplification of trade documentation.

\section{- Access to Information}

Accurate and timely information on, for example, market opportunities, financial assistance and access to technology is crucial for SMEs to compete and grow in a global market environment. This is an important role that both the government and relevant business organizations can play.

In addition to these key areas for capacity building, others relate to the development of business networks, including the development of strategic alliances and joint ventures, and the ability to be innovative.

\section{- Inter-firm networking}

Entrepreneurs who develop and maintain ties with other entrepreneurs tend to outperform those who do not. A network is a group of firms using combined resources to cooperate on joint projects. Business networks take different forms and serve different objectives. Some are structured and formal, even having their own legal personality. Others are informal, where, for instance, groups of firms share ideas or develop broad forms of cooperation. Some aim at general information-sharing while others address more specific objectives (such as joint export ventures). Soft networks generally encompass a larger number of firms than hard networks, with membership often open to all that meet a minimum requirement (such as payment of an annual fee). Networks have come to encompass agreements with research bodies, education and training institutions and public authorities. Hard networks are more commercially focused, involving a limited number of preselected firms, sometimes formally and tightly linked through a joint venture or strategic alliance. Networks can allow accelerated learning. Moreover, peer-based learning - which networks permit - is the learning medium of choice for many small firms. Furthermore, to innovate, entrepreneurs often need to reconfigure relations with suppliers, which networks can facilitate. Networks can allow the sharing of overhead costs and the exploitation of specific scale economies present in collective action. Networks need not be geographically concentrated. Once trust among participants is established, and the strategic 
direction agreed, operation dialogue could be facilitated through electronic means.

\section{- Innovation}

Recent studies have shown that, despite the fact that a very small fraction of total business R\&D in the developed economies is accounted for by SMEs, they contribute greatly to the innovation system by introducing new products and adapting existing products to the needs of their customers (OECD, 2000a). Small firms account for a disproportionate share of new product innovation despite their low R\&D expenditures (Acs and Audretsch, 1990). In addition, they have also been innovative in terms of improved designs and product processes and in the adoption of new technologies. Investment in innovative activities is on the rise in SMEs and is increasing at a faster rate than that for large firms. Scherer (1991) has suggested that SMEs possess a number of advantages relative to large firms when it comes to innovative activity. First, they are less bureaucratic than highly structured organisations. Second, many advances in technology accumulate on a myriad of detailed inventions involving individual components, materials and fabrication techniques. The sales possibilities for making such narrow, detailed advances are often too small to interest large firms. Third, it is easier to sustain high interest in innovation in small organizations where the links between challenges, staff and potential rewards are tight. Firms in the developed high-cost economies can no longer compete in labour-intensive areas of production where they have lost their comparative advantage, but rather must shift into knowledgebased economic activities where comparative advantage is compatible with both high wages and high levels of employment. This emerging comparative advantage is based on innovative activity. For the developed economies of East Asia, their future international competitiveness will also depend upon their ability to develop, and have a capacity in, knowledge-intensive firms, many of which will be SMEs based upon the experience of the developed OECD economies.

\section{The Role of Government}

In addition to fostering market liberalization and securing appropriate framework conditions, governments also have an important role in promoting entrepreneurship; facilitating firm start-up and expansion (and not hindering exit); improving access to venture capital and other types of financing; improving access of new firms and SMEs to information, innovation networks and business services; reducing the regulatory burden on smaller firms; and promoting enterprise 
partnerships, networks and clusters of international, national and local-level small firms.

Regional governments have an important role to play in the capacity building of their small businesses. While government strategies to assist SME capacity building depend upon the country's stage of development, there are some basic principles of successful SME development strategies emphasizing a market-oriented approach (see Hallberg, 2000). First, the establishment of a level playing field. The fundamental key to a successful SME development strategy is the establishment of a business environment that helps SMEs compete on a more equal basis. To establish a level playing field, governments need to re-evaluate the costs and benefits of regulations that place a disproportionate burden on SMEs, implement regulations with the flexibility needed by SMEs, and place greater emphasis on competition and procurement policies to open SME access to markets. Second, to target public expenditure carefully in order to use scarce public resources effectively. Governments need to design a clear, coordinated strategy for SME development that carefully separates equity and efficiency objectives. Public expenditure should be confined to those services and target groups that are underserved by the market and for which there is a clear justification based on public goods or equity considerations. Using the methodology of micro-finance, good practice in the delivery of services to SMEs can be judged according to the performance criteria of coverage, cost-effectiveness, financial sustainability and impact. Third, to encourage the private provision of a wide array of financial and non-financial services. In most developing countries, SMEs do not have access to institutions and instruments appropriate to their needs. To ensure SMEs have access to a diverse range of financial and non-financial services, governments should strive to develop private markets for services suitable for SMEs, stimulating market development on both the demand and the supply side.

Government assistance can also play an important role in the business and exporting success of SMEs through access to finance, infrastructure provision, the provision of training programmes, reducing bureaucracy and establishing a pro-business environment, and the staging of seminars and trade fairs. Support at the local level through investment in infrastructure that assists directly the business efficiency of small business is important. Examples include transport and information technology infrastructure, both of which are important for export success. Policy makers also need to focus on removing barriers affecting trade. Barriers to trade for small businesses are not just tariff related, however, but also involve issues of product presentation standards, warehousing and financial transactions. Because small businesses lack the economies of scale and the internal expertise of larger businesses, they need more practical external support. 


\subsection{GLOBALIZATION AND EXPORT SUCCESS}

\subsubsection{Stairway to Export Success}

The key drivers of export success for small businesses can be usefully described using the model of export development as set out in Figure 1.1. This model identifies four key components of export success: ability, attitude, stimuli and learning. The four components of the stairway to export success are not necessarily sequential, hence there is no one set track to export success. Firms can venture into exporting at different stages of their development and by different means. It is possible for some businesses to be 'born global' and identify their export market very early in the development of their business, while others may only look for an export opportunity after they have consolidated their domestic market, and then attempt to increase turnover or see improved margins. Others only contemplate exporting when confronted by a customer from another country seeking to access a particular product.

A key step towards export success relates to company fundamentals or core competencies. This would include the possession of strategic assets or competencies that provide the business with a unique product or process, upon which the enterprise can capitalize through the development of domestic and overseas markets. The skills (IT for example) and abilities of the management and workforce are also another key ingredient. The introduction of the Internet, together with good communications and transport infrastructure, now makes it possible to sell the firm's product to global customers. The flexibility and innovation association with the enterprise can be another firm asset. Finally, access to finance in order to develop and fully exploit the core competencies of the enterprise itself is important.

A second key ingredient is the attitude of the owner-manager of the business in terms of desire and commitment to the successful development of the business: ability to have an outlook for the future development of the business beyond that of the domestic market, and the perceptions towards risk. That is the attitude towards the development of markets overseas relative to that of merely focusing upon the domestic market, and the willingness to take risks in developing markets overseas.

A third component relates to stimuli to exporting. This could occur externally to the enterprise arising from a marketing opportunity, or the result of internal decision-making within the business to seek out exporting opportunities. The stimuli could be proactive or reactive.

The final component relates to the development of exporting skills, including those of developing partnerships; market selection and development; strategy development; and the development of logistics and operations. 


\section{EXPORT}

\section{SUCCESS}

\section{Ability}

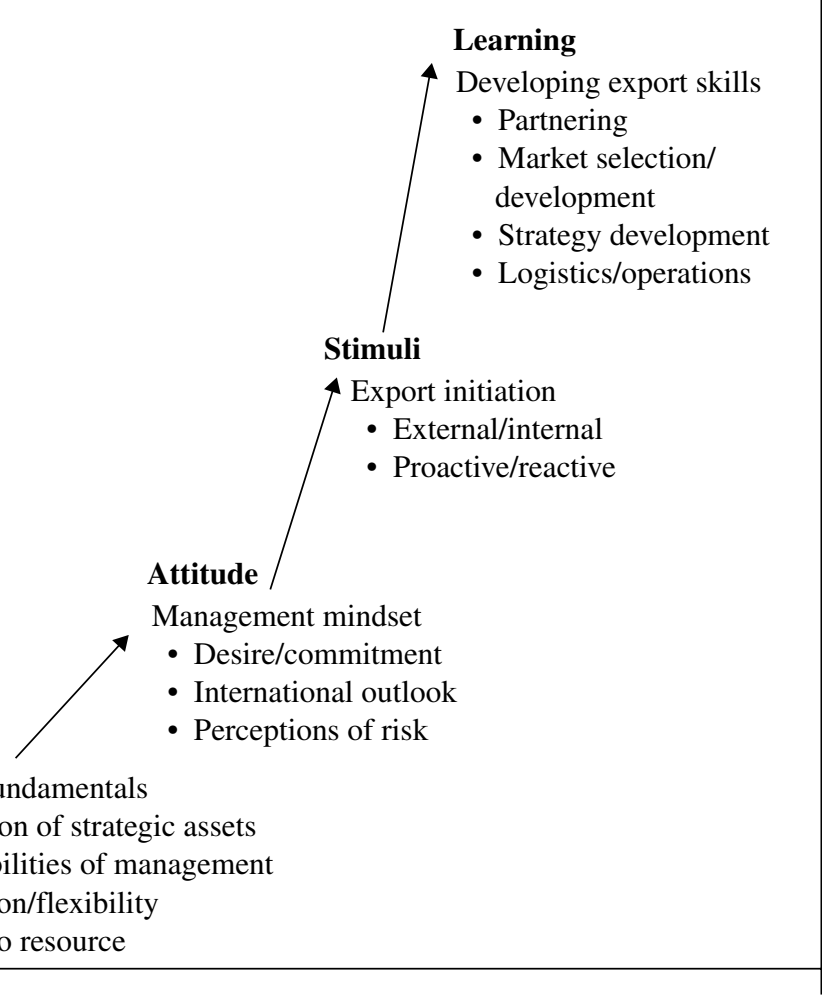

Source: Exporter community, identifying potential exporters, literature review, Hall (2002b).

Figure 1.1 Stairway to export success

\subsubsection{Competitiveness Strategies}

As many of the economies in East Asia develop further, for example, Singapore, Hong Kong, Taiwan and Korea and the newly industrializing economies of Malaysia, Thailand and Indonesia, they will increasingly find it difficult to compete in labour-intensive, low-skilled and low value added activities. The ability of their SMEs to create, access and commercialize knowledge on global markets will become an increasingly important source of their new competitiveness in global markets. Based upon the experiences of developed country members of the OECD, some of the 
principal competitiveness strategies that have been used by innovative SMEs in these countries have included the following (see OECD, 2000a, p. 11):

- Innovation strategy, in which SMEs try to appropriate returns from their knowledge base (which may or may not involve own investments in R\&D).

- Information technology strategy, which makes innovative uses of information technology in order to reduce SME costs and increase productivity.

- Niche strategy, in which SMEs choose to become sophisticated global players in a narrow product line.

- Network strategy, in which SMEs work and cooperate with other firms, be they SMEs or large enterprises, in order to improve their ability to access and absorb innovations.

- Cluster strategy, in which SMEs locate in close proximity with competitors in order to take advantage of knowledge spillovers, especially in the early stages of the industrial life cycle (OECD, 2000b).

- Foreign direct investment strategy, in which SMEs exploit firmspecific ownership advantages overseas.

Membership of clusters and inter-firm networks can enhance the productivity, rate of innovation and competitive performance of firms. Clusters and networks can allow small firms to combine the advantages of small scale (flexibility) with the benefits of large scale (economies of scale) (OECD, 2000b). A clusters policy provides a framework for dialogue and cooperation between firms, the public sector (local and regional governments) and non-governmental organizations. This dialogue can lead to efficiency-enhancing collaboration amongst firms, such as in joint marketing initiatives, the creation of mutual credit guarantee associations, joint design and sponsorship of training, a more efficient division of labour amongst firms and so on. In a period of globalization, inter-firm networks hold the promise of allowing small firms to compete on a par with larger companies. Networks can allow firms to engage in accelerated - and peerbased - learning. They can facilitate the reconfiguration of relationships with suppliers, and offer scope for increased efficiency through collective action. As with clusters, networks can pave the way for greater specialization amongst small firms, opening opportunities for economies of scope and scale. While not all networks need be geographically concentrated, networking of different sorts is central to the competitive advantage derived from membership of a cluster. 


\subsection{IMPLICATIONS FOR POLICY}

This chapter has briefly reviewed the strategic importance of SMEs to the sustained growth and development of the East Asian economy, key issues relating to the building of their capacity to grow and export, and key issues relating to their export success and strategies for global competitiveness. In the process a number of key issues for policy makers were identified.

First, SMEs (generally those enterprises with less than 100 employees) are important to economic growth, and are especially important to jobs and job creation. SMEs already contribute over half the private sector jobs in the East Asian region, and about 70 per cent of new job creation seems to be coming from SMEs. In developing economies the contribution of SMEs to employment tends to be higher, around 70 per cent of the workforce, but as economies develop to higher income per head levels, the contribution to employment by SMEs tends to decline to around 50 per cent. In developing economies the jobs tend to be created more by start-ups, but in the developed economies jobs seem to be created more by high-growth SMEs. It is important for policy makers to understand and to foster the way this 'entrepreneurial engine' works and evolves.

Second, the entrepreneurial engine in developing East Asia is underpowered. The job-creating potential of SMEs is less than it could be. There are about 2 billion people in East Asia, and about 20 million SMEs. In most of the developed economies there are about 20 people per SME, but in developing East Asia there are about 100 people per SME. This means that the ability to create jobs by start-ups is greater, and the pool of SMEs from which fast-growth SMEs emerge is smaller. This is largely due to historical and political reasons; for example, China and Vietnam have only recently pursued policies to stimulate SME growth, and there is a lot of catching up to do. Policy makers in both the developing and developed economies need to work with the private sector to address this aspect of catch-up.

Third, internationally, SMEs have more opportunities than ever before, but they seem to be growing only at about the same rate as the international economy. SMEs contribute about 30 per cent or so of direct exports, about what they contributed at the start of the 1990s, but this is less than might be expected in an increasingly globalized economy. Part of the problem here is the paucity of statistics on SME international activity. Part of it is that the trade barriers that have been addressed so far by APEC and WTO tend to favour larger trading firms, and do not address the more specific non-border non-trade impediments that SMEs tend to be obstructed by when operating across borders. These impediments need to be identified and addressed more aggressively. 
Fourth, SMEs have tended to become more important economically and politically. SMEs are given political recognition by most national and provincial governments because they employ so many people. However, politically, SMEs have tended to be taken for granted by many national governments because they are a relatively weak domestic political force. Only since the early 1990s have SMEs had the real choice of being able to internationalize, just as larger enterprises did in the 1950s and 1960s. SMEs, especially those fast-growth SMEs that contribute much to economic and employment growth, can increasingly decide where to locate their business activity. This is very much a two-edged sword for policy makers. However they need to see that as much as 70 per cent of the longer-term growth for their economies comes from SMEs, and that there is a need to work together to build an attractive and conducive entrepreneurial business environment in the region and, more specifically, in their own economies.

Fifth, key to the future success of SMEs will be capacity building which will enable them to take advantage of the market opportunities that arise from the process of globalization and from greater economic integration within East Asia and APEC more generally. In particular SMEs and regional governments will need to focus upon attaining greater access to markets, technology, skilled human resources, finance and information. In addition their competitiveness and capacity can be further enhanced through the nurturing of networks and by becoming more innovative in terms of both new products and services as well as processes. The role of government is crucial. It will be required to find means for enhancing SME access to finance, new technology and encouraging the take-up of e-commerce by SMEs through improved telecommunications infrastructure; to provide training programmes in the requisite skills for SMEs; to open up domestic markets and reduce non-tariff barriers in trade with other countries.

Finally, there is no single track to SME exporting success. This will vary depending upon the circumstances of the SME - its product, industry, internal skills and motivations, as well as access to resources. In the future there will be an increasing need as regional economies develop to ensure that SMEs become more innovative in terms of both product and processes. The creation, access and commercialization of knowledge will increasingly provide the basis for the future global competitiveness of regional firms both large and small. The increasing economic integration of regional economies, and ongoing developments in information and communications technology, will provide market opportunities for SMEs that, if taken advantage of, will enable them to be the economic powerhouse of the region into the future.

A primary objective of the remainder of this book is to elaborate further upon a number of these issues: the contribution of SMEs to sustained 
economic recovery and poverty alleviation; strategies for SME development; internationalization strategies including usage of the Internet; public policy and SME sector development; and the importance of access to venture capital.

\subsection{STRUCTURE OF THE BOOK}

The book is organized according to four broad sub-themes: general and macro aspects, internal (micro) aspects, strategic aspects and policy aspects.

\section{General and Macro Aspects}

In the first section of the book, the contributions are focused on broader issues relating to SMEs, and to issues and lessons arising from the experience of the Asian economic crisis of 1997-98. In Chapter 2, Hock-Beng Cheah and Melanie Cheah present a thoughtful analysis of the concept of sustainable development in the economic sphere. They reject the orthodox model of development, which they argue is prone to crisis, has little meaning for a substantial proportion of the world's population, has generated considerable inequities and, perhaps more significantly, may prove unsustainable in the longer term. Cheah and Cheah suggest that the alternative is to be found in the notion of what they call a 'diversified production system', or DPS, which they contrast with the mass production system (MPS) that has held sway in many economies in the last century. Some of the characteristics of the DPS include goods and services of 'any kind', that are potentially available at 'no charge', 'anytime', 'anywhere', and with the facility to 'do it yourself'.

The authors argue that momentous changes are already in progress that point in the direction of such a DPS. Furthermore, they argue, this directional shift holds great significance for SMEs whose characteristics of spontaneity, flexibility, diversity and multiplicity may allow them to capitalize sufficiently on the DPS to substantially offset the current difficulties faced by their economies. In addition, because of their significance in employment terms (SMEs account in most countries for more than half, and in some cases as much as 90 per cent, of the labour force), they represent an important force for promoting upward social mobility and reduction of social inequalities in times of economic growth. The ability of SMEs to carry out their economic functions sustainably and to connect via local clusters with the global economy may therefore engender a different mode of production that will have far more encouraging results for sustainability than has been the case under the orthodox model of development. 
Charles Harvie then takes up, in Chapter 3, the related theme of economic recovery and poverty alleviation, and, in particular, the role of micro-enterprises in East Asia. Although micro-enterprises occupy the extreme small end of the size spectrum of businesses, they represent a highly significant avenue of employment and economic opportunity for relatively disadvantaged groups in many countries - particularly the poor and women, many of whom have no other means of livelihood. However, micro-enterprises themselves tend to be disadvantaged in a variety of ways, including government policies that are often biased against them in favour of larger firms, and lack of access to market information, to opportunities for skills development and, crucially, to credit. Harvie looks at the various types of micro-enterprises in East Asia, and argues that it is important to differentiate between the different types in the formulation of policy. He identifies two distinct types of micro-enterprise: (1) livelihood enterprises, which do not generate much employment and are unlikely to grow, but whose development and growth as a whole can generate more employment as well as alleviate poverty; and (2) growth-oriented micro-enterprises, which have the potential to grow and to be sustainable in terms of income and employment generation, and for that reason represent a better prospect for the longer-term development of their economies.

Harvie goes on to examine how micro-enterprises, with appropriate micro-finance support, can contribute to the attainment of four major economic and social development objectives: poverty reduction, empowerment of women, employment generation and private sector enterprise development. This is an important issue because micro-enterprise development contributes to a widening of the pool of entrepreneurship available to society, increases the number of direct participants in the development process, and broadens the base of the private sector. Harvie argues that micro-finance institutions can play an important role for both major types of micro-enterprise.

In Chapter 4, Dudley Jackson focuses on the importance of uniform international standards for the purpose of assessing both economic sectors and economic enterprises. In the case of sectors, the exercise promotes transparency in the economy and in addition may provide earlywarning signals of impending problems; in the case of enterprises, such assessment will be necessary if and when an enterprise reaches the stage where it feels ready to approach the capital markets for external funding. Jackson discusses the development of the United Nations System of National Accounts 1993, which brought about changes to the reporting of balance-of-payments statistics and of government transactions under the Government Finance Statistics framework. He then discusses assessment measures that may be applied to the 'enterprise sector' of the economy. 
The move towards an internationally standardized system of reporting of economic activity is surely a positive development that will promote the comparison and benchmarking of both economic sectors and enterprises, with associated benefits in terms of transparency and good governance.

Elias Sanidas then examines, in Chapter 5, the comparative story of economic growth in the US and Japan in terms of the organization of firms and industries in the two countries. Using a novel approach, he reaches two major conclusions. First, economies such as Japan and Italy which had more pronounced competition elements, as proxied by the number of SMEs in each country, experienced higher growth rates than those such as the US and Germany. Second, inter-firm economies of scope and nonintegration were a major moving force behind Japan's higher economic performance, contrary to the intra-firm economies of scale and scope and vertical integration of American firms. These findings have implications for industrial and competition policy insofar as they suggest that a more intensely competitive environment comprising many firms in each industry is more likely to produce benefits in the form of higher growth rates; this in turn has direct implications for SME policy.

Philippe Régnier's study, in Chapter 6, of how SMEs in Thailand coped with the financial crisis that engulfed the country (and the wider region) in 1997-98, is of great interest for the insights it provides into the sources of the resilience of small firms, and the strategies they employed, for example through their links with large transnational corporations (TNCs), during difficult times. Indeed, as he points out, it was the SMEs with links to TNCs that proved the most resilient, particularly in Thailand, during the crisis. For example, he documents the case of TNCs which maintained a sustainable level of orders from their most reliable SME suppliers in order to prevent them from falling into bankruptcy, offered delayed terms of payment for deliveries and facilitated SME access to credit facilities by not only introducing them to foreign bankers but also acting as guarantors highlighting the value of the 'dense interpersonal networks' maintained by the businesses concerned. Ironically, as Régnier notes, in the case of the Thai SMEs, Japanese and overseas Chinese financial networks provided more support than did the Thai commercial bankers. He concludes by examining the lessons to be learnt from the experiences of the Thai SMEs during this period.

\section{Internal (Micro) Aspects}

The second section of the book comprises two chapters, on two issues which may not ordinarily be at the forefront of SME managers' concerns because of their philosophical nature, but which are nonetheless important. 
Llandis Barratt-Pugh's chapter explores the relationship between our changing concepts of knowledge and the resulting implications for organizational growth, with particular emphasis on SMEs. The development of new knowledge, as he points out, is at the heart of organizational competition. He reports on a research study that explores the values held by managers in organizations concerning training, learning and knowledge development, and examines the potential for managing knowledge development within SMEs.

In Chapter 8, Za'faran Hassan and Arawati Agus investigate the ethical ideologies of owner-managers of Malaysian SMEs regarding the perceived importance of ethics in their business operations, based on a survey of Malaysian SMEs in the state of Selangor. Two main issues investigated are, first, the question of whether a business believes it is ultimately responsible to its stockholders or to its various stakeholders and, second, the personal moral philosophies of the managers surveyed. The key findings are that SME owner-managers tend to score higher on the stockholder view as compared to the stakeholder view, and that they tend to hold more idealistic views as compared to relativistic ones. These findings are explained by the authors in terms of cultural factors.

\section{Strategic Aspects}

The third section of the book turns to the strategic aspects of business decisions facing SMEs. Two of the contributions, those by Susan Freeman and by Heru Satyanugraha, study the attempts by SMEs to expand beyond their domestic markets; the chapter by Paul Robertson, Thomas Keil and Erkko Autio looks at informational sourcing strategies of Australian SMEs; while Bob Ritchie and Clare Brindley investigate the comparative Internet strategies of SMEs in China and the UK.

Two reviews of the literature on the internationalization of firms are provided, by Freeman in Chapter 9, and by Satyanugraha in the following chapter. Freeman notes that recent research has tended to shift from a focus on SMEs and exporting to focusing on the processes and patterns that explain how firms increase their international involvement over time, and how relationship networks may be involved in this process. The applicability of the research to SMEs is open to question because it has tended to concentrate on large multinationals. Not much research has been carried out on the internationalization decision process of smaller firms, though she foreshadows also that network approaches for market selection and entry decisions may yield useful insights. Satyanugraha's chapter on the entry mode decisions of Indonesian SMEs nicely complements Freeman's and in addition provides some concrete results from a survey of 
more than 200 Indonesian small and medium-sized manufacturers of industrial goods.

The chapter by Paul Robertson, Thomas Keil and Erkko Autio begins with the observation that access to external sources of information and knowledge can improve the ability of firms, especially smaller ones, to learn and to increase their efficiency and competitiveness. The authors review the ways in which technological knowledge can be obtained externally by firms from both suppliers and customers, then go on to explore how SMEs in Australia, a geographically isolated country with relatively low levels of domestic R\&D activity, cope with their need for external information and knowledge. There is widespread fear among Australian firms of losing competitive knowledge to rivals through networks; the authors suggest that there is potential for them to gain from increased networking behaviour and that government policy should be geared towards encouraging not just formal networks but also other looser forms of 'embeddedness', considering carefully what sorts of relationships between firms are likely to lead to the largest gains in innovative learning. This is a finding reached also by Harvie and Lee in Chapter 13.

An aspect of strategy that is becoming increasingly important is the incorporation of the Internet as part of the competitive approach of SMEs. This is the subject of Chapter 12, by Bob Ritchie and Clare Brindley, who surveyed SMEs in the UK and in Beijing, China on how the businesses currently (at the time of the survey) or prospectively viewed the application of the Internet as fitting into their strategies in terms of market competition and supply chain management. Their findings that both groups of SMEs viewed the Internet primarily as a marketing communications tool to promote their products and services is not a surprising one. As they point out, the study provides merely a snapshot in a rapidly evolving environment, but it is nonetheless important to form an idea of usage patterns and perceptions of the Internet within SMEs.

\section{Policy Aspects}

The fourth section of the book is a collection of three chapters on aspects of policy. In the first of these, Charles Harvie and Boon-Chye Lee examine the arguments for government intervention in markets for the purpose of providing assistance to SMEs in a range of activities. Their review suggests that many of the arguments put forward for subsidizing SME activities (as distinct from some activities of firms regardless of size) are not economically justified. Nonetheless, it is widely acknowledged that SMEs suffer from disadvantages relative to large firms, principally in the areas of access to information and technology. They then examine the possibilities 
offered by networks in helping SMEs deal with the disadvantages they experience, indicating that there are benefits firms can derive from participating in networks. Further, because networks can assist firms to overcome some of their inherent disadvantages, they can become less reliant on public assistance and more able to compete on an equal footing with larger firms once the initial impetus is provided for the formation of cooperative networks that can enable firms to compete more effectively.

Three conclusions are reached regarding policies targeted at encouraging cooperative networks of SMEs. First, policies should seek to encourage the establishment of these links and networks. Further, while it is not clear what role policy plays in the process of encouraging the formation of firm networks, some decentralization of policy to regional and local government seems warranted in the case of geographical clusters and industrial districts. Second, if public assistance to SMEs is deemed justified, delivery of this assistance to a network is more cost-effective than assistance to individual enterprises, as transaction costs are lower. Third, given the disadvantages that smaller firms tend to suffer in terms of access to better-qualified personnel, policy emphasis can usefully be placed on upgrading the skills of small firms. The issues considered in this part of the chapter therefore relate closely to those looked at by Robertson, Keil and Autio in Chapter 11.

In Chapter 14, Russell Smyth reviews the policies of local governments in China aimed at fostering collective township and village enterprises (CTVEs), the Chinese equivalent of SMEs. Unlike other East Asian economies, where SME policies have been implemented by central government, in China it is local governments that have taken on this function. Smyth argues that as monitoring costs have increased, local governments have adopted indirect forms of governance over CTVEs while retaining direct control over the most profitable firms.

Barbara Cornelius and Sandra Van Der Laan round off the section (and the volume) with their chapter on venture capital policy. Their comparative survey of policies takes in the experiences, both positive and negative, of seven countries. The major lesson the authors draw from this is that well thought out, comprehensive policies with clear objectives that are appropriate to the culture of the societies they are meant to serve (rather than simply imported wholesale from another country), stand a better chance of success.

\section{REFERENCES}

Acs, Z.J. and D.B. Audretsch (1990), Innovation and Small Firms, Cambridge, MA: MIT Press.

APEC (1998), 'Profile of SMEs in East Asia' (available at http://www.actetsme.org) 
Hall, C. (1999a), 'Using the international entrepreneurial engine to restart Asian growth', in Leo Paul Dana (ed.), International Entrepreneurship, an Anthology, Singapore: NTU Entrepreneurship Development Centre.

Hall, C. (1999b), 'The challenges and the opportunities of e-commerce and international SMEs; implications for HRM in APEC', paper to the APEC HRM Symposium, Kaohsiung, 29-31 October.

Hall, C. (2000), 'E-commerce and SMEs in APEC - HRD implications and the role of PECC', paper presented to the ninth annual meeting of PECC - HRD, Pacific Economic Cooperation Council Human Resource Development Task Force, Hua, Taiwan, 21-22 October.

Hall, C. (2002a), 'Profile of SMEs and SME issues in East Asia', in C. Harvie and B.C. Lee (eds), The Role of Small and Medium Enterprises in National Economies in East Asia, Cheltenham: Edward Elgar Publishing, pp. 21-49.

Hall, C. (2002b), 'Small business and trade in APEC', a report prepared for the APEC Ministers Responsible for Trade Meeting, Puerta Vallarta, Mexico, 29-30 May.

Hallberg, K. (2000), 'A market-oriented strategy for small and medium-scale enterprises', IFC Discussion Paper No. 40, World Bank, Washington, DC.

Harvie, C. (2002), 'The Asian financial and economic crisis and its impact on regional SMEs', in C. Harvie and B.C. Lee (eds), Globalisation and Small and Medium Enterprises in East Asia, Cheltenham: Edward Elgar Publishing, pp. 10-42.

Harvie, C. and B.C. Lee (2002a) (eds), Globalisation and Small and Medium Enterprises in East Asia, Cheltenham: Edward Elgar Publishing.

Harvie, C. and B.C. Lee (2002b) (eds), The Role of Small and Medium Enterprises in National Economies in East Asia, Cheltenham: Edward Elgar Publishing.

Ministry of Economic Affairs (1999), White Paper on Small and Medium Enterprises in Taiwan, Small and Medium Enterprises Administration, Taiwan, September.

OECD (1997), Globalisation and SMEs, Vols 1 and 2, Paris: OECD.

OECD (2000a), 'Enhancing the competitiveness of SMEs through innovation', workshop paper no. 1, Bologna Meeting, OECD, Paris.

OECD (2000b), 'Local partnership, clusters, and SME globalisation', workshop paper no. 2, Bologna Meeting, OECD, Paris.

OECD (2000c), 'Realising the potential of electronic commerce, for SMEs in the global market', workshop paper no. 3, Bologna Meeting, OECD, Paris.

Pomerleano, M. (1998), 'The East Asia crisis and corporate finances: the untold micro story', mimeo, International Finance Corporation.

Scherer, F.M. (1991), 'Changing perspectives on the firm size problem', in Z.J. Acs and D.B. Audretsch (eds), Innovation and Technological Change, an International Comparison, Ann Arbor, MI: University of Michigan Press, pp. 24-38.

Tran, V.H. and C. Harvie (2000) (eds), The Causes and Impact of the Asian Financial Crisis, Basingstoke: Macmillan.

World Bank (1998), East Asia: The Road to Recovery, Washington, DC: World Bank. 